\title{
Effects of continuous glucose monitor-recorded nocturnal hypoglycaemia on quality of life and mood during daily life in type 1 diabetes
}

\author{
Marie M. Henriksen $^{1}$ (D) $\cdot$ Henrik U. Andersen ${ }^{2} \cdot$ Birger Thorsteinsson $^{1,3} \cdot$ Ulrik Pedersen-Bjergaard $^{1,3}$
}

Received: 6 May 2020 / Accepted: 26 October 2020 / Published online: 14 January 2021

(C) The Author(s), under exclusive licence to Springer-Verlag GmbH, DE part of Springer Nature 2021

\begin{abstract}
Aims/hypothesis The aim of this work was to assess the effect of spontaneous nocturnal hypoglycaemia on quality of life and mood during subsequent days in type 1 diabetes.

Methods A total of 153 people with type 1 diabetes participated in 6 days of blinded continuous glucose monitoring while documenting hypoglycaemic symptoms, quality of life and mood, daily. Hypoglycaemia was defined by interstitial glucose $\leq 3.9 \mathrm{mmol} / \mathrm{l}\left(\mathrm{IG}_{3.9}\right)$ and $\leq 3.0 \mathrm{mmol} / 1\left(\mathrm{IG}_{3.0}\right)$ for $\geq 15 \mathrm{~min}$ and was classified as asymptomatic if no hypoglycaemic symptoms were reported.

Results Self-estimated quality of life assessed by the EQ-5D VAS (but not by the WHO Well-Being Index) was higher the day after asymptomatic (but not after symptomatic) hypoglycaemic nights, as compared with non-hypoglycaemic nights $\left(\mathrm{IG}_{3.9}, p=\right.$ $\left.0.021 ; \mathrm{IG}_{3.0}, p=0.048\right)$. The effect increased with lower glucose nadir and longer duration of nocturnal hypoglycaemia $\left(\mathrm{IG}_{3.9}\right.$, $p=0.03$ ). The finding was confined to participants with impaired hypoglycaemia awareness. There was no effect of nocturnal hypoglycaemia on mood or self-estimated effectiveness at work the following day.

Conclusions/interpretation Individuals with type 1 diabetes and impaired hypoglycaemia awareness reported higher quality of life on days preceded by nights with asymptomatic (but not symptomatic) hypoglycaemia. The effect was amplified by lower glucose nadir and longer duration of the episodes and may help explain resistance to implementation of interventions to reduce hypoglycaemia in many people with impaired hypoglycaemia awareness.
\end{abstract}

Keywords Hypoglycaemia · Hypoglycaemia awareness · Impaired awareness · Quality of life · Type 1 diabetes

$\begin{array}{ll}\text { Abbreviations } & \\ \text { CGM } & \text { Continuous glucose monitoring } \\ \text { EQ-5D VAS } & \text { EuroQol-5D visual analogue scale } \\ \mathrm{IG}_{3.0} & \text { Interstitial glucose } \leq 3.0 \mathrm{mmol} / 1 \\ \mathrm{IG}_{3.9} & \text { Interstitial glucose } \leq 3.9 \mathrm{mmol} / 1 \\ \text { QoL } & \text { Quality of life } \\ \text { SMBG } & \text { Self-monitoring of blood glucose } \\ \text { TIR } & \text { Time in range }\end{array}$

Marie M. Henriksen

marie.moth.henriksen@regionh.dk

1 Department of Endocrinology and Nephrology, Nordsjællands Hospital, Hillerød, Denmark

2 Steno Diabetes Center Copenhagen, Gentofte, Denmark

3 Department of Clinical Medicine, Faculty of Health and Medical Sciences, University of Copenhagen, Copenhagen, Denmark
UWIST University of Wales Institute of Science and Technology

\section{Introduction}

The experience of hypoglycaemia is generally believed to affect people with diabetes in a negative manner [1,2]. Thus, several retrospective studies demonstrate that selfreported hypoglycaemia is associated with poorer quality of life (QoL) in type 1 diabetes [1,3-5], an effect amplified by the frequency and severity of the hypoglycaemic episodes [3, $5,6]$. Nocturnal experimental hypoglycaemia is shown to reduce QoL the following day [7]. A few survey studies compare the effect of nocturnal vs daytime hypoglycaemic events on QoL and find that people with self-reported nocturnal mild hypoglycaemia report poorer QoL compared with those reporting daytime hypoglycaemia $[3,5]$. 


\section{Research in context}

\section{What is already known about this subject?}

- Symptomatic hypoglycaemia has profound biological and psychological effects on people with diabetes

- Neuroimaging studies show different brain activation patterns in people with normal and impaired hypoglycaemia awareness

- Little is known about the impact of nocturnal hypoglycaemia (particularly asymptomatic hypoglycaemia) on day-to-day quality of life in type 1 diabetes

\section{What is the key question?}

- Does preceding spontaneous nocturnal hypoglycaemia impact day-to-day quality of life and mood in individuals with type 1 diabetes and, if so, does hypoglycaemia awareness influence this?

\section{What are the new findings?}

- Quality of life is improved the day following a night with asymptomatic hypoglycaemia in people with type 1 diabetes and impaired hypoglycaemia awareness

- The effect is incremental for both lower glucose nadir and longer duration of the hypoglycaemic episode

\section{How might this impact on clinical practice in the foreseeable future?}

- The findings demonstrate a potentially complex interplay between biological and psychological effects of hypoglycaemia, which may result in differences in perceptions of, and attitudes towards, hypoglycaemia among people with diabetes. It is important to acknowledge these factors when designing and implementing interventions to prevent hypoglycaemia

Also, mood may be affected by hypoglycaemia in type 1 diabetes. A prospective study shows that people with severe hypoglycaemia chronically have a higher level of anxiety and depression compared with people without severe hypoglycaemia but no acute effects of the episodes per se [8]. Other studies explore the consequences of symptomatic mild hypoglycaemia on mood in type 1 diabetes $[9,10]$ and find that mood shifts towards unhappiness and a less energetic and tenser state $[9,10]$.

Previous research mainly focuses on the consequences of symptomatic hypoglycaemia, which, on one hand, may be a product of biological effects of hypoglycaemia on the brain and, on the other hand, may be psychological effects arising from the participants' knowledge of the episodes. Little is known about the impact of asymptomatic hypoglycaemia. Since the majority of hypoglycaemic episodes in type 1 diabetes are asymptomatic $[11,12]$, these episodes may potentially have a major impact on QoL, mood and effectiveness during daily life.

Studies applying advanced neuroimaging modalities to assess the effect of hypoglycaemia on brain function show that people with impaired awareness of hypoglycaemia may react differently to hypoglycaemia compared with people with normal hypoglycaemia awareness [13, 14], suggesting diverse biological effects of hypoglycaemia.

The aim of this study was to investigate the impact of preceding spontaneous nocturnal hypoglycaemia (asymptomatic, in particular) on QoL, mood and effectiveness during the following days in type 1 diabetes. Furthermore, we aimed to explore potential differences in QoL responses according to state of hypoglycaemia awareness.

\section{Methods}

The study was a prospective observational study approved by the Danish Data Protection Agency and the Regional Committee on Biomedical Research Ethics (H-15002715). Written informed consent was obtained from all participants. A detailed description of the study design has been published previously [12].

\section{Participants}

A total of 153 adults ( $\geq 18$ years old) with type 1 diabetes duration of at least 1 year were recruited consecutively in the outpatient clinic at Nordsjællands Hospital Hillerød, Denmark. Individuals with concomitant malignant disease or end-stage renal disease, or those who were pregnant, were excluded from the study. The baseline characteristics of the participants are shown in Table 1.

\section{Study design}

Following recording of baseline characteristics and blood sampling, the participants underwent 6-7 days of blinded 
Table 1 Characteristics of participants with type 1 diabetes

\begin{tabular}{|c|c|}
\hline Characteristic & Value \\
\hline$N$ & 153 \\
\hline Male sex, $n(\%)$ & $90(59)$ \\
\hline Age, years & $52 \pm 14$ \\
\hline Duration of diabetes, years & $22 \pm 15$ \\
\hline C-peptide negative, $n(\%)^{\mathrm{a}}$ & $108(71)$ \\
\hline BMI, $\mathrm{kg} / \mathrm{m}^{2}$ & $26 \pm 4$ \\
\hline Total insulin dose, U/day & $47 \pm 22$ \\
\hline \multicolumn{2}{|l|}{ Insulin therapy, $n(\%)$} \\
\hline Analogue & $123(80.4)$ \\
\hline Analogue/human & $22(14.4)$ \\
\hline Human & $8(5.2)$ \\
\hline \multicolumn{2}{|l|}{ Insulin treatment regimen, $n(\%)$} \\
\hline 1-3 daily injections & $6(4)$ \\
\hline$\geq 4$ daily injections & $117(76)$ \\
\hline CSII & $30(20)$ \\
\hline \multicolumn{2}{|l|}{$\mathrm{HbA}_{1 \mathrm{c}}$} \\
\hline $\mathrm{mmol} / \mathrm{mol}$ & $64 \pm 12$ \\
\hline$\%$ & $8.0 \pm 1.1$ \\
\hline \multicolumn{2}{|l|}{ Hypoglycaemia awareness classification, $n(\%)$} \\
\hline \multicolumn{2}{|l|}{ Gold [16] } \\
\hline Aware & $121(79)$ \\
\hline Reduced awareness & $31(20)$ \\
\hline \multicolumn{2}{|l|}{ Clarke [17] } \\
\hline Aware & $106(69)$ \\
\hline Unclassified & $20(13)$ \\
\hline Reduced awareness & $22(14)$ \\
\hline \multicolumn{2}{|l|}{ Hillerød [18] } \\
\hline Aware & $71(46)$ \\
\hline Impaired awareness & $59(39)$ \\
\hline Unaware & $22(14)$ \\
\hline $\begin{array}{l}\text { Episodes of severe hypoglycaemia (per person, over } \\
\text { previous year) }\end{array}$ & $\begin{array}{l}0.3 \pm 1.0 ; 0 \\
\quad(0-8)\end{array}$ \\
\hline $\begin{array}{l}\text { Episodes of mild symptomatic hypoglycaemia (per } \\
\text { person, over previous week) }\end{array}$ & $\begin{array}{l}1.9 \pm 2.5 \\
\quad 1(0-16)\end{array}$ \\
\hline
\end{tabular}

Values are mean \pm SD or median (range), unless indicated otherwise

${ }^{a} \mathrm{C}$-peptide $<20 \mathrm{pmol} / \mathrm{l}$ was undetectable

CSII, continuous subcutaneous insulin infusion

continuous glucose monitoring (CGM), while they continued their usual daily activities and treatments. During the monitoring period, the participants documented episodes of symptomatic hypoglycaemia $(\leq 3.9 \mathrm{mmol} / \mathrm{l})$. Daily activities, food intake and insulin dosing were recorded every half hour in a diary. A detailed questionnaire was filled in by the participants regarding each episode of hypoglycaemia, including whether they had symptoms or not.

The device used for CGM was blinded iPro 2 with Enlite Glucose sensors (Medtronic MiniMed, Northridge, CA, USA), which has a reported overall mean absolute relative difference (MARD) of $13.9 \%$ and $18.4 \%$ in the hypoglycaemic range (glucose level $\leq 3.9 \mathrm{mmol} / \mathrm{l}$ ), a sensitivity of $90.1 \%$ and a positive predictive value of $83.8 \%$ for hypoglycaemia [15]. Calibration was performed according to the manufacturer's recommendations (four times daily) with blood glucose meter measurements (Contour XT meter using Contour NEXT test strips; Bayer, Basel, Switzerland).

\section{Questionnaires}

At entry into the study, the participants filled in questionnaires regarding self-estimated state of hypoglycaemia awareness according to three validated methods: Gold [16]; Clarke [17]; and Hillerød [18]. Furthermore, the questionnaire asked the participant to state the number of episodes of severe hypoglycaemia experienced in the preceding year. Severe hypoglycaemia was defined as an episode where assistance from another person was needed to restore glucose levels to normal [2]. History of diabetes, treatments (medications, use of technologies) and late diabetic complications were collected from the participants' medical records or asked for as appropriate. $\mathrm{HbA}_{1 \mathrm{c}}$ and C-peptide levels were measured (participants with undetectable levels $(<20 \mathrm{pmol} / \mathrm{l})$ were categorised as C-peptide negative).

Every evening participants filled in questionnaires regarding QoL, mood and self-estimated effectiveness at work. QoL was assessed by the WHO-5 Well-Being Index [19] and the EuroQol-5D visual analogue scale (EQ-5D VAS) [20]. In both questionnaires, the participants score between 0 and 100 , with higher scores indicating higher QoL. A difference in score of $\geq 7$ on the EQ-5D VAS is reported to be a clinically important change in QoL [21]. Changes in mood were evaluated by the University of Wales Institute of Science and Technology (UWIST) Mood Adjective Checklist [22]. This checklist describes three main mood states: energetic arousal (feeling active rather than tired); tense arousal (feeling anxious vs relaxed); and hedonic tone (feeling happy vs sad). Selfestimated effectiveness at work was assessed hourly using a Likert-type visual analogue scale of 1 (not effective) to 7 (very effective).

\section{CGM analysis}

An episode of hypoglycaemia was classified as an episode with continuous interstitial glucose values below two threshold levels: interstitial glucose $\leq 3.9 \mathrm{mmol} / \mathrm{l}\left(\mathrm{IG}_{3.9}\right)$, as formerly recommended by the ADA; and interstitial glucose $\leq 3.0 \mathrm{mmol} / 1\left(\mathrm{IG}_{3.0}\right)$, as suggested by the International Hypoglycaemia Study Group and endorsed by ADA and the EASD [2, 23-25]. A valid hypoglycaemic event was defined by glucose values below the thresholds for $\geq 15 \mathrm{~min}$, and recovery from hypoglycaemia was defined as interstitial glucose values continuously above the threshold for 
$\geq 20 \min [23,24,26]$. An episode of hypoglycaemia without self-reported symptoms of hypoglycaemia in the diary was classified as asymptomatic. The hypoglycaemic nadir of an episode was defined as the lowest interstitial glucose value during the episode. Night-time was defined as 11:00 hours to 07:00 hours. To assess whether daytime and night-time hyperglycaemia had an effect on QoL, an episode of significant hyperglycaemia was defined as glucose levels continuously $>14 \mathrm{mmol} / 1$ for $\geq 15 \mathrm{~min}[23,24]$. Time in range (TIR) was defined as the percentage of time spent with a glucose level 4-10 mmol/1 [23, 24].

\section{Statistical analysis}

A total of 153 patients were included but QoL data were not reported for two patients and awareness status was unknown for one patient, so $n$ ranged from 150 to 153 in analyses. This study was an explorative study, so no power calculations could be made. We used standard descriptive statistics to characterise participants. Median and range are presented in addition to mean $\pm \mathrm{SD}$, when distribution of data is skewed. The Mixed Models analysis was used to investigate the effect of prior nocturnal hypoglycaemia on QoL, mood and effectiveness the day after. The Mixed Models analysis enables adjustment for correlation due to repeated observations (i.e. 6 days of CGM) on each participant. For categorical variables, the resulting estimate (i.e. increase or decrease in scores on the questionnaires) and $p$ values indicate comparison of nights without hypoglycaemia vs hypoglycaemic nights (reference: non-hypoglycaemic nights). For quantitative variables, the estimate and $p$ values indicate the increase per increment of the variable. The following variables were included in the model: episode of hypoglycaemia the preceding night (present or not) and duration of hypoglycaemic episodes (per $15 \mathrm{~min}$ increment [i.e. the shortest duration of a hypoglycaemic episode]). All variables were assessed in total as well as separated into asymptomatic and symptomatic nocturnal hypoglycaemia. To assess the influence of possible confounders we also included the following variables in the model: TIR (daytime); episode of daytime hyperglycaemia (present or not); episode of nocturnal hyperglycaemia (present or not); fasting morning selfmonitoring of blood glucose (SMBG), categorised into three groups (hypoglycaemic morning $\mathrm{SMBG} \leq 3.9 \mathrm{mmol} / 1$ $\left[\mathrm{SMBG}_{\leq 3.9}\right]$, morning SMBG in range $\left[\mathrm{SMBG}_{4-10}\right.$; glucose levels of 4-10 mmol/l] and hyperglycaemic morning SMBG $>10 \mathrm{mmol} / 1\left[\mathrm{SMBG}_{>10}\right]$ ); and $\mathrm{HbA}_{1 \mathrm{c}}$. Non-parametric tests were used to compare daytime glycaemic variables on days with and without prior nocturnal hypoglycaemia.

Analyses were performed with SPSS software package (version 25.0; IBM, Armonk, NY, USA), and a $p$ value $<0.05$ (two-sided) was chosen as level of statistical significance.

\section{Results}

\section{Occurrence of nocturnal hypoglycaemia}

The 153 participants were monitored for a total of 1040 days and nights, resulting in $6.1 \pm 0.9$ (mean $\pm \mathrm{SD}$ ) days and nights per person of valid recording of CGM (total duration minus periods of time with failure to record [ $0.5 \%$ of the total recording duration]). During the study, $54 \%$ of the participants had one or more nights with hypoglycaemia. There was at least one episode of nocturnal hypoglycaemia at threshold $\mathrm{IG}_{3.9}$ in 141 nights (14\%), and at threshold $\mathrm{IG}_{3.0}$ in 83 nights (8\%). Asymptomatic nocturnal hypoglycaemia occurred in 102 nights $(10 \%)$ at threshold $\mathrm{IG}_{3.9}$ and in 60 nights $(6 \%)$ at threshold $\mathrm{IG}_{3.0}$. Symptomatic nocturnal hypoglycaemic episodes occurred at $\mathrm{IG}_{3.9}$ in 40 nights $(4 \%)$ and at $\mathrm{IG}_{3.0}$ in 24 nights (2\%). The duration of nocturnal hypoglycaemic episodes (mean $\pm \mathrm{SD}$ ) was $181 \pm 120$ min (median [range], 150 [20-535] $\mathrm{min}$ ) at $\mathrm{IG}_{3.9}$, and $147 \pm 107 \mathrm{~min}$ (median [range], 125 [20-450] $\mathrm{min}$ ) at $\mathrm{IG}_{3.0}$. The duration of asymptomatic hypoglycaemic episodes was $192 \pm 122$ min (median [range], 173 [20-535] $\mathrm{min}$ ) at $\mathrm{IG}_{3.9}$, and $160 \pm 109$ min (median [range], 140 [20-450] min) at $\mathrm{IG}_{3.0}$. The duration of symptomatic episodes was $158 \pm 119$ min (median [range], 115 [20-465] $\mathrm{min}$ ) at $\mathrm{IG}_{3.9}$, and $127 \pm 117 \mathrm{~min}$ (median [range], $76[20-450] \mathrm{min})$ and $\mathrm{IG}_{3.0}$.

\section{QoL following nocturnal hypoglycaemia}

EQ-5D VAS The participants reported significantly higher selfestimated QoL, indicated by higher scores on the EQ-5D VAS, after hypoglycaemic nights as compared with after nonhypoglycaemic nights when analysed at both threshold $\mathrm{IG}_{3.9}$ and threshold $\mathrm{IG}_{3.0}$ (Table 2). The effect size on QoL increased with decreasing hypoglycaemic levels. However, hypoglycaemic nights with glucose measurements between 3.0 and $3.9 \mathrm{mmol} / 1$ did not have a significant effect on $\mathrm{QoL}$ the following day (score difference: 1.9 [95\% CI $-0.88,4.6]$, $p=0.18$ ). The effect on EQ-5D VAS increased with longer total duration of nocturnal hypoglycaemia (score increase per 15 min increment in hypoglycaemic duration: 0.14 [95\% CI $0.01,0.27$ ],$p=0.032$, for $\mathrm{IG}_{3.9}$; and 0.23 [95\% CI 0.02 , 0.44 ], $p=0.030$, for $\mathrm{IG}_{3.0}$ ). However, the duration of episodes with glucose measurements between 3.0 and $3.9 \mathrm{mmol} / \mathrm{l}$ did not influence EQ-5D VAS $(0.07$ [95\% CI $-0.20,0.34], p=0.55)$. The effect of nocturnal hypoglycaemia on EQ-5D VAS was limited to the day following the event, as no association was present on the second day following the event $(p=0.59)$.

Separate analysis of nights with asymptomatic or symptomatic hypoglycaemia showed that the association was present after nights with asymptomatic hypoglycaemia (Table 2). In contrast, there was no difference in QoL following nights with symptomatic hypoglycaemia compared with nights 
Table 2 QoL (assessed by the EQ-5D VAS and by the WHO-5 Well-Being Index) following overall, asymptomatic and symptomatic nocturnal hypoglycaemia at thresholds $\mathrm{IG}_{3.9}$ and $\mathrm{IG}_{3.0}$ in participants with type 1 diabetes

\begin{tabular}{|c|c|c|c|c|}
\hline \multirow[t]{2}{*}{ Hypoglycaemia status } & \multicolumn{2}{|l|}{ EQ-5D VAS } & \multicolumn{2}{|c|}{ WHO-5 Well-Being Index } \\
\hline & Mean scores $(95 \% \mathrm{CI})$ & $p^{\mathrm{a}}$ & Mean scores $(95 \% \mathrm{CI})$ & $p^{\mathrm{a}}$ \\
\hline \multicolumn{5}{|l|}{ Overall } \\
\hline $\mathrm{IG}_{3.9}$ & & 0.027 & & 0.494 \\
\hline $\mathrm{NH}$ & $83.0(80.3,85.8)$ & & $71.1(68.7,75.5)$ & \\
\hline Non-NH & $80.9(78.7,83.1)$ & & $71.2(68.7,73.7)$ & \\
\hline $\mathrm{IG}_{3.0}$ & & 0.013 & & 0.170 \\
\hline $\mathrm{NH}$ & $84.0(80.9,87.2)$ & & $73.5(69.5,77.5)$ & \\
\hline Non-NH & $80.9(78.7,83.2)$ & & $71.1(68.6,73.6)$ & \\
\hline \multicolumn{5}{|l|}{ Asymptomatic } \\
\hline $\mathrm{IG}_{3.9}$ & & 0.021 & & 0.575 \\
\hline $\mathrm{NH}$ & $83.5(80.5,86.5)$ & & $72.1(68.4,75.9)$ & \\
\hline Non-NH & $80.9(78.7,83.1)$ & & $71.2(68.7,73.7)$ & \\
\hline $\mathrm{IG}_{3.0}$ & & 0.048 & & 0.401 \\
\hline $\mathrm{NH}$ & $83.9(80.4,87.4)$ & & $72.9(68.4,77.4)$ & \\
\hline Non-NH & $81.0(78.8,83.2)$ & & $71.2(68.7,73.7)$ & \\
\hline \multicolumn{5}{|l|}{ Symptomatic } \\
\hline $\mathrm{IG}_{3.9}$ & & 0.794 & & 0.698 \\
\hline $\mathrm{NH}$ & $81.6(77.6,85.7)$ & & $72.3(66.7,77.8)$ & \\
\hline Non-NH & $81.2(78.9,83.4)$ & & $71.3(68.8,73.8)$ & \\
\hline $\mathrm{IG}_{3.0}$ & & 0.144 & & 0.220 \\
\hline $\mathrm{NH}$ & $84.3(79.6,89.0)$ & & $74.9(68.7,81.1)$ & \\
\hline Non-NH & $81.1(78.9,83.3)$ & & $71.2(68.7,73.7)$ & \\
\hline
\end{tabular}

without. The duration of asymptomatic nocturnal hypoglycaemia was positively associated with scores on EQ-5D VAS; participants at threshold $\mathrm{IG}_{3.9}$ scored 0.16 (95\% CI $0.02,0.31)$ higher $(p=0.030)$ on the EQ-5D VAS per $15 \mathrm{~min}$ increment in duration of preceding nocturnal hypoglycaemia. The same result was found at threshold $\mathrm{IG}_{3.0}$, with a score of 0.27 (95\% CI 0.04, $0.51)$ higher $(p=0.022)$ per $15 \mathrm{~min}$ increment in duration of preceding nocturnal hypoglycaemia. The duration of symptomatic nocturnal hypoglycaemia was not associated with QoL $\left(p=0.84\right.$ for $\mathrm{IG}_{3.9} ; p=0.80$ for $\left.\mathrm{IG}_{3.0}\right)$. Neither the duration of asymptomatic nor symptomatic nocturnal events with glucose measurements solely between $3.0 \mathrm{mmol} / 1$ and $3.9 \mathrm{mmol} / \mathrm{l}$ was associated with scores on the $\operatorname{ED}-5 \mathrm{D} \operatorname{VAS}(p=0.70$ and $p=0.05$, respectively).

WHO-5 Well-Being Index Neither previous nocturnal hypoglycaemia $\left(\mathrm{IG}_{3.9}, p=0.49 ; \mathrm{IG}_{3.0}, p=0.17\right)$ (Table 2) nor the total duration of hypoglycaemia $\left(\mathrm{IG}_{3.9}, p=0.55 ; \mathrm{IG}_{3.0}, p=0.53\right)$ were associated with QoL assessed by the WHO-5 Well-Being Index the subsequent day. Scores on the individual questions on the WHO Well-Being Index were not associated with prior nocturnal hypoglycaemia, including the question regarding quality of sleep (all $p>0.05$ ).

\section{Mood following nocturnal hypoglycaemia}

All three mood states of the UWIST Mood Adjective Checklist scored similarly on days after hypoglycaemic nights and nights without hypoglycaemia (all $p>0.05$ ). Likewise, the duration of hypoglycaemic nocturnal episodes was not associated with the mood the subsequent day. The results were similar at both threshold levels of hypoglycaemia $\left(\mathrm{IG}_{3.9}\right.$ and $\left.\mathrm{IG}_{3.0}\right)$.

\section{Effectiveness at work following nocturnal hypoglycaemia}

Participants' self-estimated effectiveness at work the day following a night with a hypoglycaemic event did not differ from the effectiveness on days after nights without hypoglycaemia $\left(\mathrm{IG}_{3.9}, p=0.75 ; \mathrm{IG}_{3.0}, p=0.12\right)$. Furthermore, the duration of hypoglycaemic episodes $\left(\mathrm{IG}_{3.9}\right.$, $p=0.43 ; \mathrm{IG}_{3.0}, p=0.07$ ) did not correlate to the participants' self-estimated effectiveness. 


\section{State of awareness and QoL following nocturnal hypoglycaemia}

Overall QoL assessed by the EQ-5D VAS (i.e. independent of occurrence of preceding nocturnal hypoglycaemia) decreased with decreasing state of hypoglycaemia awareness (EQ-5D VAS scores [mean \pm SD]: normal awareness, $82.3 \pm 15.3$; impaired awareness, $80.9 \pm 16.6$; unawareness, $76.9 \pm 16.7 ; p=$ 0.001). Participants with normal awareness assessed by the Hillerød method [18] had similar scores on the EQ-5D VAS following asymptomatic hypoglycaemic nights and nonhypoglycaemic nights (Table 3, Fig. 1). Participants with impaired awareness or unawareness (as characterised by the Hillerød method) scored 3.0 (95\% CI $0.5,5.5)$ higher on the EQ-5D VAS at $\mathrm{IG}_{3.9}(p=0.017)$ for nights with vs without hypoglycaemia; the difference increased to 4.8 (95\% CI 1.7 , $7.9 ; p=0.003)$ at $\mathrm{IG}_{3.0}$. Limiting the analysis to participants with hypoglycaemia unawareness according to the Hillerød method showed $10.4\left(\mathrm{IG}_{3.0}[95 \% \mathrm{CI} 2.6,18.1]\right)$ higher scores $(p=0.014)$ on the EQ-5D VAS the day following a hypoglycaemic asymptomatic night as compared with nights without hypoglycaemia (Table 3, Fig. 1). The same was seen in participants with reduced awareness according to the Clarke method, where EQ-5D VAS score was $7.4\left(\mathrm{IG}_{3.0}[95 \% \mathrm{CI} 0.6,14.1]\right)$ higher $(p=0.032)$ after asymptomatic hypoglycaemic nights compared with after nonhypoglycaemic nights. No effect was observed in participants classified as having impaired awareness by the Gold method $(p=0.34)$ at threshold $\mathrm{IG}_{3.0}$ (data not shown). There was no effect of symptomatic nocturnal hypoglycaemia in any of the awareness classes (Table 3). Moreover, there was no association between asymptomatic nocturnal events with glucose measurements solely between $3.0 \mathrm{mmol} / \mathrm{l}$ and $3.9 \mathrm{mmol} / \mathrm{l}$ and scores on the ED-5D VAS in any of the awareness classes (normal awareness, $p=0.29$; impaired awareness and unawareness combined, $p=0.20$ ).

\section{Influence of daytime CGM-recorded glycaemia, nocturnal hyperglycaemia and SMBG on QoL}

According to the CGM data, occurrence of both asymptomatic and symptomatic episodes of daytime hyperglycaemia $(p=$ $0.80)$ and daytime hypoglycaemia $\left(\mathrm{IG}_{3.9}, p=0.30 ; \mathrm{IG}_{3.0}\right.$, $p=0.38$ ) did not influence QoL reported according to the EQ-5D VAS scale the same evening. Adjustment for these daytime glucose excursions did not alter the effect of prior nocturnal asymptomatic hypoglycaemia on QoL. Furthermore, daytime TIR was not associated with changes in EQ-5D VAS $(p=0.12)$. Occurrence of daytime

Table 3 State of hypoglycaemia awareness (according to the Hillerød Method) and QoL (assessed by the EQ-5D VAS) following overall, asymptomatic and symptomatic episodes of nocturnal hypoglycaemia at the $\mathrm{IG}_{3.9}$ and $\mathrm{IG}_{3.0}$ thresholds

\begin{tabular}{|c|c|c|c|c|c|c|}
\hline \multirow[t]{2}{*}{ Nocturnal hypoglycaemia status } & \multicolumn{2}{|l|}{ Normal awareness } & \multicolumn{2}{|l|}{ Impaired awareness } & \multicolumn{2}{|l|}{ Unawareness } \\
\hline & Mean scores $(95 \% \mathrm{CI})$ & $p^{\mathrm{a}}$ & Mean scores $(95 \% \mathrm{CI})$ & $p^{\mathrm{a}}$ & Mean scores $(95 \% \mathrm{CI})$ & $p^{\mathrm{a}}$ \\
\hline \multicolumn{7}{|l|}{ Overall } \\
\hline $\mathrm{IG}_{3.9}$ & & 0.529 & & 0.054 & & 0.162 \\
\hline $\mathrm{NH}$ & $83.3(79.2,87.4)$ & & $82.8(78.4,87.2)$ & & $81.8(73.9,89.6)$ & \\
\hline Non-NH & $82.3(79.2,85.5)$ & & $80.4(76.4,84.3)$ & & $77.1(71.4,82.8)$ & \\
\hline $\mathrm{IG}_{3.0}$ & & 0.919 & & 0.103 & & 0.008 \\
\hline $\mathrm{NH}$ & $82.6(77.8,87.4)$ & & $83.1(78.3,88.0)$ & & $87.2(73.2,96.1)$ & \\
\hline Non-NH & $82.4(79.3,85.6)$ & & $80.5(76.5,84.4)$ & & $76.8(70.9,82.7)$ & \\
\hline \multicolumn{7}{|l|}{ Asymptomatic } \\
\hline $\mathrm{IG}_{3.9}$ & & 0.444 & & 0.073 & & 0.150 \\
\hline $\mathrm{NH}$ & $83.9(79.1,88.7)$ & & $82.9(78.3,87.5)$ & & $82.2(74.0,90.4)$ & \\
\hline Non-NH & $82.4(79.2,85.5)$ & & $80.4(76.5,84.4)$ & & $77.1(71.4,82.8)$ & \\
\hline $\mathrm{IG}_{3.0}$ & & 0.697 & & 0.313 & & 0.014 \\
\hline $\mathrm{NH}$ & $81.4(75.4,87.4)$ & & $82.5(77.3,87.6)$ & & $87.0(77.7,96.4)$ & \\
\hline Non-NH & $82.5(79.4,85.6)$ & & $80.6(76.7,84.5)$ & & $76.7(70.8,82.6)$ & \\
\hline \multicolumn{7}{|l|}{ Symptomatic } \\
\hline $\mathrm{IG}_{3.9}$ & & 0.941 & & 0.714 & & 0.922 \\
\hline $\mathrm{NH}$ & $82.6(77.4,87.8)$ & & $81.7(75.2,88.2)$ & & $78.6(60.1,97.1)$ & \\
\hline Non-NH & $82.4(79.3,85.6)$ & & $80.7(76.8,84.7)$ & & $77.7(72.1,83.4)$ & \\
\hline $\mathrm{IG}_{3.0} \mathrm{~b}$ & & 0.577 & & 0.148 & & \\
\hline $\mathrm{NH}$ & $84.0(77.7,90.3)$ & & $85.1(78.0,92.2)$ & & - & \\
\hline Non-NH & $82.4(79.3,85.5)$ & & $80.6(76.7,84.6)$ & & - & \\
\hline
\end{tabular}

${ }^{a} p$ values indicate comparison of nights without hypoglycaemia vs hypoglycaemic nights (reference: non-hypoglycaemic nights), assessed via Mixed Models analysis

${ }^{\mathrm{b}}$ Too few hypoglycaemic nights for analysis in 'unawareness' group

$\mathrm{NH}$, hypoglycaemic night; non-NH, non-hypoglycaemic night 
a
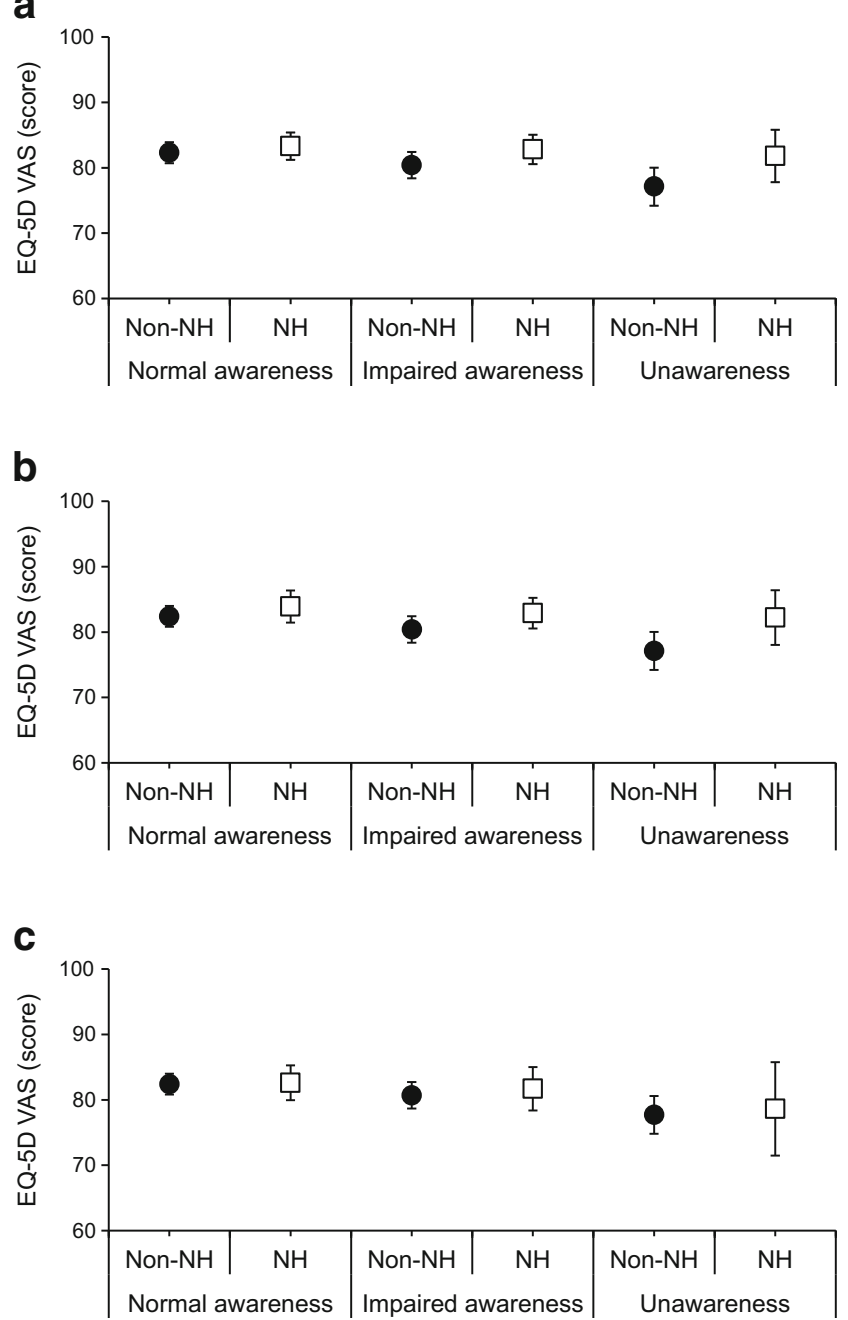

Fig. 1 QoL assessed by the EQ-5D VAS following nocturnal hypoglycaemia at thresholds $\mathrm{IG}_{3.9}(\mathbf{a}-\mathbf{c})$ and $\mathrm{IG}_{3.0}(\mathbf{d}-\mathbf{f})$ in 150 people with type 1 diabetes according to state of hypoglycaemia awareness (normal awareness, $n=69$; impaired awareness, $n=59$; unawareness, $n=22$; assessed by the Hillerød method [18]). NH, hypoglycaemic nights; non-NH, non-hypoglycaemic nights. (a) Any episode of nocturnal hypoglycaemia $\left(\mathrm{IG}_{3.9}\right)$. Comparison between groups (non-NH vs $\mathrm{NH}$ ): normal awareness, $p=0.53$; impaired awareness, $p=0.05$; unawareness, $p=0.16$. (b) Asymptomatic nocturnal hypoglycaemia $\left(\mathrm{IG}_{3.9}\right)$. Non-NH vs NH: normal awareness, $p=0.44$; impaired awareness, $p=0.07$; unawareness, $p=0.15$. (c) Symptomatic nocturnal hypoglycaemia

hypoglycaemia and hyperglycaemia was similar on days with and without prior nocturnal hypoglycaemia $(p=0.59$ and $p=$ 0.69 , respectively). Moreover, TIR during the daytime was not related to occurrence of prior nocturnal hypoglycaemia $(p=0.66)$.

According to the EQ-5D VAS score the following day, QoL was not affected by either occurrence of nocturnal hyperglycaemia $(p=0.53)$ or occurrence of episodes with a glucose level between $4 \mathrm{mmol} / \mathrm{l}$ and $5 \mathrm{mmol} / \mathrm{l}(p=0.27)$.

Lower fasting morning SMBG was associated with better QoL (EQ-5D VAS score [95\% CI]: $\mathrm{SMBG}_{\leq 3.9}, 83.1$ [79.6,

\section{d}
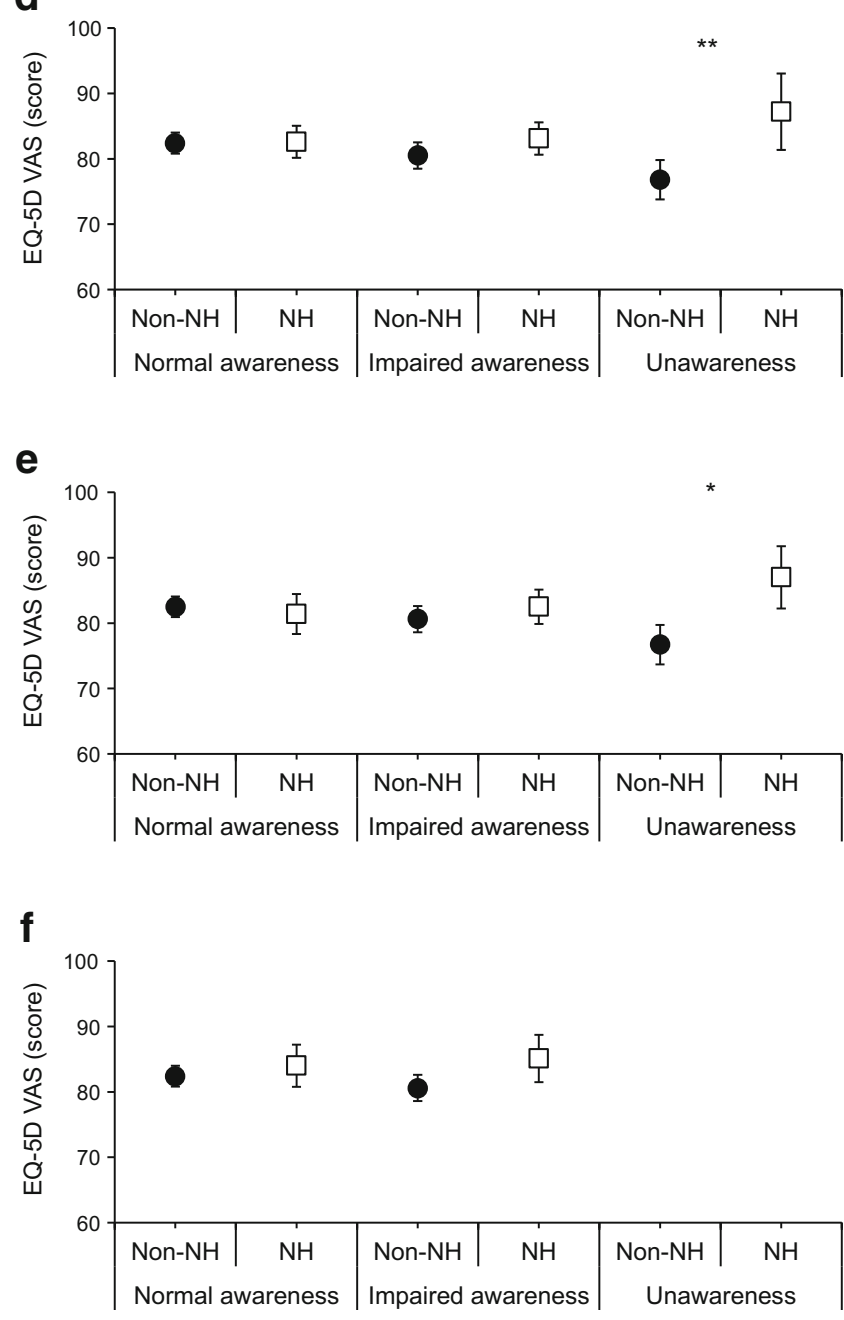

$\left(\mathrm{IG}_{3.9}\right)$. Non-NH vs NH: normal awareness, $p=0.94$; impaired awareness, $p=0.71$; unawareness, $p=0.92$. (d) Any episode of nocturnal hypoglycaemia $\left(\mathrm{IG}_{3.0}\right)$. Non-NH vs $\mathrm{NH}$ : normal awareness, $p=0.92$; impaired awareness, $p=0.10$; unawareness, $p=0.008$. (e) Asymptomatic nocturnal hypoglycaemia $\left(\mathrm{IG}_{3.0}\right)$. Non-NH vs NH: normal awareness, $p=0.70$; impaired awareness, $p=0.31$; unawareness, $p=$ 0.014. (f) Symptomatic nocturnal hypoglycaemia $\left(\mathrm{IG}_{3.0}\right)$. Non-NH vs $\mathrm{NH}$ : normal awareness, $p=0.58$; impaired awareness, $p=0.15$. There were too few symptomatic hypoglycaemic nights at $\mathrm{IG}_{3.0}$ in the group with hypoglycaemia unawareness for analysis. Data are mean $\pm \mathrm{SEM}$. ${ }^{*} p<0.05,{ }^{* *} p<0.01, \mathrm{NH}$ vs non-NH

86.5]; $\mathrm{SMBG}_{4-10}, 82.1[79.8,84.5] ; \mathrm{SMBG}_{>10}, 80.1$ [77.7, 82.6]; $p=0.029)$. Separate analysis of the effect of fasting morning SMBG by awareness state showed that the effect of morning SMBG on QoL was only present for participants with normal awareness (EQ-5D VAS score [95\% CI]: $\mathrm{SMBG}_{\leq 3.9}, 86.2[80.8,91.6] ; \mathrm{SMBG}_{4-10}, 83.9$ [CI 80.5, 87.2]; $\mathrm{SMBG}_{>10}, 81.4$ [78.0, 84.8]; $p=0.042$ ) and not for participants with impaired awareness or unawareness, as assessed by the Hillerød method (score [95\% CI]: $\mathrm{SMBG}_{\leq 3.9}, 80.8$ [76.1, 85.5]; $\mathrm{SMBG}_{4-10}, 80.6$ [77.2, 84.0]; $\left.\mathrm{SMBG}_{>10}, 78.9[75.3,82.4] ; p=0.31\right)$. 


\section{Discussion}

In the present study, QoL measured daily in the evening by the EQ-5D VAS was increased on days preceded by asymptomatic, but not symptomatic, nocturnal hypoglycaemia detected by blinded CGM. The QoL increment was 'dose-dependent' as it increased both with lower glucose nadir and longer duration of the hypoglycaemic episode, and it was transient as it was not present on the second day after the event. Furthermore, the effect was consistently confined to individuals with impaired hypoglycaemia awareness.

Overall, no clear glucose threshold for the effect of asymptomatic hypoglycaemia on QoL the following day was demonstrated. However, there was no effect of tight nocturnal glycaemic control and no significant effect of level 1 episodes with nadir between 3.0 and $3.9 \mathrm{mmol} / \mathrm{l}$. This supports the present consensus on a glycaemic level of less than $3.0 \mathrm{mmol} / \mathrm{l}$ (level 2) for clinically important CGM-detected hypoglycaemia $[23,25]$.

To our knowledge, this is the first study to examine the impact of spontaneous mild nocturnal hypoglycaemia detected by blinded CGM on day-to-day changes in QoL in type 1 diabetes. The finding that asymptomatic hypoglycaemia has an impact on QoL in real life may have great importance for people with type 1 diabetes as most episodes of nocturnal hypoglycaemic are asymptomatic [11, 12]. Since blinded CGM is used in our study, the effect of asymptomatic hypoglycaemia on QoL cannot be affected by participants having recognised the episodes. This suggests a biological effect of asymptomatic hypoglycaemia on QoL, which may be very different from the negative psychological effects previously reported to be associated with symptomatic nocturnal hypoglycaemia $[3,5,6]$.

Other studies based on questionnaires retrospectively examining self-reported symptomatic hypoglycaemic episodes $[3,5,6]$ or experimental studies exploring the effect of insulin-induced hypoglycaemia [7, 10, 27, 28] show that hypoglycaemia is associated with poorer QoL, mood and cognitive function. In our study, there was no impact of symptomatic nocturnal hypoglycaemia on QoL or other selfreported outcomes. This may be due to differences in the used methodologies, including QoL measures and timing of the assessments in relation to the hypoglycaemic events. Thus, if the assessment had instead been performed in the morning as in other studies $[7,10,27,28]$ it may have confirmed a negative impact of symptomatic hypoglycaemia.

People with impaired awareness had the lowest overall QoL assessed by the EQ-5D VAS. As these people have many-fold higher rates of severe hypoglycaemia, this is in accordance with the reported chronic negative impact of severe hypoglycaemia on QoL [5]. The positive impact of asymptomatic nocturnal hypoglycaemia on QoL was confined to the participants with the most impaired awareness who scored 10.3 higher on the EQ-5D VAS following nights with asymptomatic hypoglycaemia at $\mathrm{IG}_{3.0}$, a difference well above 7 , which is regarded as clinically important [21].

The concept that people with impaired awareness may react differently to hypoglycaemia compared with those with normal awareness is supported by a number of studies [29, 30] investigating the effect of experimental insulin-induced mild hypoglycaemia [29] and state of awareness [30] on brain function. The studies show that adaptive changes (or habituation) in the cerebral responses to hypoglycaemia (with attenuated symptomatic response) may occur in individuals with impaired awareness [13, 14, 31-34]. These changes may include altered fuel transport and brain metabolism with use of alternative fuels during hypoglycaemia with neuroglycopenia. Lactate is suggested as an alternative fuel when glucose levels are low in the brain, albeit only in people with impaired awareness consistent with a metabolic adaptation to recurrent hypoglycaemia in the brain $[35,36]$. Further changes include deactivation of areas associated with fear, distress and perception of hypoglycaemia as an important experience (e.g. amygdala, ventral striatum, medial orbital cortex) and increased activation of areas associated with reward sensations (lateral orbitofrontal cortex) [13, 33]. Thus, hypoglycaemia (with attenuated symptomatic response) in unaware individuals seemingly does not lead to appropriate fear and discomfort as seen in aware individuals but paradoxically may have a positive rewarding effect. Clinically, this is supported by studies demonstrating that individuals with unawareness of hypoglycaemia, who often are heavily exposed to asymptomatic hypoglycaemia, may be surprisingly unconcerned about their state of unawareness [37], and a subset of individuals with type 1 diabetes has low fear of hypoglycaemia despite carrying a high risk of severe episodes of hypoglycaemia [38]. Furthermore, interventions to reduce hypoglycaemia risk can be difficult to implement due to resistance in some individuals with impaired awareness [39]. Taken together, the evidence suggests a paradoxical pleasant or rewarding effect of hypoglycaemia on the brain in people with severely impaired awareness at an unconscious level.

The finding was not explained by an effect of prior nocturnal hypoglycaemia on daytime glycaemic profiles. Neither were they explained by tight nocturnal glycaemic control, subsequent glycaemic excursions during the day or the morning fasting plasma glucose, nor by the occurrence of preceding nocturnal hyperglycaemia. However, participants with normal awareness reported better QoL with lower fasting glucose values.

We only found a positive effect of previous nocturnal hypoglycaemia on QoL assessed by the ED-5D VAS scale and not by the WHO-5 Well-Being Index. This may be explained by the fact that the ED-5D VAS scale is a questionnaire designed to assess short-term changes in QoL [20] whereas the WHO-5 Well-Being Index is developed to show changes in QoL during a 1 week time span [19]. Therefore, the 
ED-5D VAS is probably more sensitive for detecting day-today variations resulting from previous nocturnal hypoglycaemia.

We were unable to show an effect of prior nocturnal hypoglycaemia (neither symptomatic nor asymptomatic) on mood states the following day in real life. An explanation may be that any changes in mood have recovered during the day before testing in the evening. This is supported by studies with insulin-induced mild symptomatic hypoglycaemia [10] and severe hypoglycaemia [8] in type 1 diabetes showing that recovery of mood states occurred within $30 \mathrm{~min}$ after restoration of euglycaemia following mild experimental hypoglycaemia [10] and within 1.5 days after an episode of severe hypoglycaemia [8].

Likewise, self-reported work efficiency was not affected by prior nocturnal hypoglycaemia. Cognitive performance is impaired during experimentally induced (both asymptomatic and symptomatic) hypoglycaemia in type 1 diabetes [28, 29] and is supposed to recover 20-75 min after restoration of euglycaemia $[9,40,41]$, thus being less likely to be reflected in the evening assessment of work efficiency.

The strength of the present study is that it is based on blinded CGM data rather than SMBG. Furthermore, it is based on prospective assessment of the impact of spontaneous hypoglycaemia on QoL during daily life rather than the impact of retrospectively self-reported episodes of hypoglycaemia. A limitation to the study is the lack of data regarding sleep duration and quality. Another limitation shared with other CGM-based studies is the validity of nocturnal hypoglycaemic episodes recorded by CGM. Thus, in the early era of CGM the use of first-generation devices occasionally resulted in detection of spurious events. However, this problem is reduced with newer CGM technology including the device used in this study [42]. Moreover, the clear dose dependency of the effect of asymptomatic hypoglycaemia supports the validity of the result.

In conclusion, people with type 1 diabetes and impaired hypoglycaemia awareness transiently report improved QoL following nights with asymptomatic (but not symptomatic) hypoglycaemia. This effect, which is probably biological, increases with depth and duration of the hypoglycaemic event and lasts for only 1 day. The finding illustrates that there may exist a complex interplay between biological and psychological effects of hypoglycaemia, which may contribute to differences in perceptions of and attitudes to hypoglycaemia among people with diabetes. Understanding this day-to-day interplay is important when designing and implementing psychobehavioural interventions to prevent hypoglycaemia [43] and deserves further scientific attention.

Acknowledgements The authors thank the participants and the staff at the research unit at Nordsjællands Hospital for their contributions. Some of the data were presented as an abstract at the ADA Scientific Congress in 2019.
Data availability The data analysed during the trial are not available.

Funding This work was supported in part by unrestricted research grants from Nordsjællands Hospital, The Jascha Foundation, The Danish Medical Research Grant and the Toyota Foundation, Denmark.

Authors' relationships and activities HUA owns stocks in Novo Nordisk, has served on advisory boards for Novo Nordisk, Abbott and Astra Zeneca, and has received lecture fees from Nordic Infucare. UPB has served on advisory boards for AstraZeneca, Bristol-Myers Squibb, Sanofi-Aventis, Novo Nordisk and Zealand Pharma and has received lecture fees from AstraZeneca, Bristol-Myers Squibb, Sanofi-Aventis and Novo Nordisk. All other authors declare that there are no relationships or activities that might bias, or be perceived to bias, their work.

Contribution statement All authors contributed to conception and design of the study. MH acquired and analysed the data, and all authors contributed to interpretation of data. MH drafted and revised the manuscript and contributed to the discussion. HUA, BT and UPB reviewed and edited the manuscript and contributed to the discussion. All authors approved the final version of the manuscript. MH is the guarantor of this work.

\section{References}

1. Jacobson AM, Braffett BH, Cleary PA, Gubitosi-Klug RA, Larkin ME, DCCT/EDIC Research Group (2013) The long-term effects of type 1 diabetes treatment and complications on health-related quality of life: A 23-year follow-up of the Diabetes Control and Complications/Epidemiology of Diabetes Interventions and Complications cohort. Diabetes Care 36:3131-3138. https://doi. org/10.2337/dc12-2109

2. Seaquist ER, Anderson J, Childs B et al (2013) Hypoglycemia and diabetes: A report of a workgroup of the American Diabetes Association and the Endocrine Society. Diabetes Care 36:13841395. https://doi.org/10.2337/dc12-2480

3. Evans M, Khunti K, Mamdani M et al (2013) Health-related quality of life associated with daytime and nocturnal hypoglycaemic events: A time trade-off survey in five countries. Health Qual Life Outcomes 11:90-7525-11-90. https://doi.org/10.1186/1477-752511-90

4. Trento M, Panero F, Porta M et al (2013) Diabetes-specific variables associated with quality of life changes in young diabetic people: The type 1 diabetes Registry of Turin (Italy). Nutr Metab Cardiovasc Dis 23:1031-1036. https://doi.org/10.1016/j.numecd. 2013.01.004

5. Harris S, Mamdani M, Galbo-Jorgensen CB, Bogelund M, Gundgaard J, Groleau D (2014) The effect of hypoglycemia on health-related quality of life: Canadian results from a multinational time trade-off survey. Can J Diabetes 38:45-52. https://doi.org/10. 1016/j.jcjd.2013.09.001

6. Levy AR, Christensen TL, Johnson JA (2008) Utility values for symptomatic non-severe hypoglycaemia elicited from persons with and without diabetes in Canada and the United Kingdom. Health Qual Life Outcomes 6:73-7525-6-73. https://doi.org/10.1186/ 1477-7525-6-73

7. King P, Kong MF, Parkin H, Macdonald IA, Tattersall RB (1998) Well-being, cerebral function, and physical fatigue after nocturnal hypoglycemia in IDDM. Diabetes Care 21:341-345. https://doi. org/10.2337/diacare.21.3.341

8. Strachan MW, Deary IJ, Ewing FM, Frier BM (2000) Recovery of cognitive function and mood after severe hypoglycemia in adults 
with insulin-treated diabetes. Diabetes Care 23:305-312. https:// doi.org/10.2337/diacare.23.3.305

9. Gold AE, MacLeod KM, Frier BM, Deary IJ (1995) Changes in mood during acute hypoglycemia in healthy participants. J Pers Soc Psychol 68:498-504. https://doi.org/10.1037/0022-3514.68.3.498

10. Hermanns N, Kubiak T, Kulzer B, Haak T (2003) Emotional changes during experimentally induced hypoglycaemia in type 1 diabetes. Biol Psychol 63:15-44. https://doi.org/10.1016/S03010511(03)00027-9

11. Agesen RM, Kristensen PL, Beck-Nielsen H et al (2018) Effect of insulin analogs on frequency of non-severe hypoglycemia in patients with type 1 diabetes prone to severe hypoglycemia: Much higher rates detected by continuous glucose monitoring than by self-monitoring of blood glucose-the HypoAna trial. Diabetes Technol Ther 20:247-256. https://doi.org/10.1089/dia.2017.0372

12. Henriksen MM, Andersen HU, Thorsteinsson B, PedersenBjergaard U (2018) Hypoglycemic exposure and risk of asymptomatic hypoglycemia in type 1 diabetes assessed by continuous glucose monitoring. J Clin Endocrinol Metab 103(6):2329-2335. https://doi.org/10.1210/jc.2018-00142

13. Dunn JT, Cranston I, Marsden PK, Amiel SA, Reed LJ (2007) Attenuation of amydgala and frontal cortical responses to low blood glucose concentration in asymptomatic hypoglycemia in type 1 diabetes: A new player in hypoglycemia unawareness? Diabetes 56:2766-2773. https://doi.org/10.2337/db07-0666

14. Mangia S, Tesfaye N, De Martino F et al (2012) Hypoglycemiainduced increases in thalamic cerebral blood flow are blunted in subjects with type 1 diabetes and hypoglycemia unawareness. J Cereb Blood Flow Metab 32:2084-2090. https://oi.org/10.1038/ jcbfm.2012.117

15. Keenan DB, Mastrototaro JJ, Zisser H et al (2012) Accuracy of the Enlite 6-day glucose sensor with guardian and Veo calibration algorithms. Diabetes Technol Ther 14:225-231. https://doi.org/10. 1089/dia.2011.0199

16. Gold AE, MacLeod KM, Frier BM (1994) Frequency of severe hypoglycemia in patients with type I diabetes with impaired awareness of hypoglycemia. Diabetes Care 17:697-703. https://doi.org/ 10.2337/diacare.17.7.697

17. Clarke WL, Cox DJ, Gonder-Frederick LA, Julian D, Schlundt D, Polonsky W (1995) Reduced awareness of hypoglycemia in adults with IDDM. A prospective study of hypoglycemic frequency and associated symptoms. Diabetes Care 18:517-522. https://doi.org/ 10.2337/diacare.18.4.517

18. Pedersen-Bjergaard U, Pramming S, Thorsteinsson B (2003) Recall of severe hypoglycaemia and self-estimated state of awareness in type 1 diabetes. Diabetes Metab Res Rev 19:232-240. https://doi. org/10.1002/dmrr.377

19. de Wit M, Pouwer F, Gemke RJ, Delemarre-van de Waal HA, Snoek FJ (2007) Validation of the WHO-5 Well-Being Index in adolescents with type 1 diabetes. Diabetes Care 30:2003-2006. https://doi.org/10.2337/dc07-0447

20. EuroQol Group (1990) EuroQol-a new facility for the measurement of health-related quality of life. Health Policy 16:199-208. https://doi.org/10.1016/0168-8510(90)90421-9

21. Walters SJ, Brazier JE (2005) Comparison of the minimally important difference for two health state utility measures: EQ-5D and SF6D. Qual Life Res 14:1523-1532. https://doi.org/10.1007/s11136004-7713-0

22. Matthews G, Jones DM, Chamberlain AG (1990) Refining the measurement of mood: The UWIST mood adjective checklist. Br J Psychol 81:17-42. https://doi.org/10.1111/j.2044-8295.1990. tb02343.x

23. Fonseca VA, Grunberger G, Anhalt $\mathrm{H}$ et al (2016) Continuous glucose monitoring: A consensus conference of the American Association of Clinical Endocrinologists and American College of
Endocrinology. Endocr Pract 22:1008-1021. https://doi.org/10. 4158/EP161392.CS

24. Danne T, Nimri R, Battelino T et al (2017) International consensus on use of continuous glucose monitoring. Diabetes Care 40:16311640. https://doi.org/10.2337/dc17-1600

25. International Hypoglycaemia Study Group (2017) Glucose concentrations of less than $3.0 \mathrm{mmol} / \mathrm{l}(54 \mathrm{mg} / \mathrm{dl})$ should be reported in clinical trials: A joint position statement of the American Diabetes Association and the Europian Association for the Study of Diabetes. Diabetologia 60:3-6. https://doi.org/10.1007/s00125016-4146-6

26. UK Hypoglycaemia Study Group (2007) Risk of hypoglycaemia in types 1 and 2 diabetes: Effects of treatment modalities and their duration. Diabetologia 50:1140-1147. https://doi.org/10.1007/ s00125-007-0599-y

27. Bendtson I, Gade J, Theilgaard A, Binder C (1992) Cognitive function in type 1 (insulin-dependent) diabetic patients after nocturnal hypoglycaemia. Diabetologia 35:898-903. https://doi.org/10.1007/ BF00399939

28. Graveling AJ, Deary IJ, Frier BM (2013) Acute hypoglycemia impairs executive cognitive function in adults with and without type 1 diabetes. Diabetes Care 36:3240-3246. https://doi.org/10. 2337/dc13-0194

29. Gold AE, MacLeod KM, Deary IJ, Frier BM (1995) Hypoglycemia-induced cognitive dysfunction in diabetes mellitus: Effect of hypoglycemia unawareness. Physiol Behav 58:501-511. https://doi.org/10.1016/0031-9384(95)00085-W

30. Hansen TI, Olsen SE, Haferstrom ECD et al (2017) Cognitive deficits associated with impaired awareness of hypoglycaemia in type 1 diabetes. Diabetologia 60:971-979. https://doi.org/10.1007/ s00125-017-4233-3

31. Bingham EM, Dunn JT, Smith D et al (2005) Differential changes in brain glucose metabolism during hypoglycaemia accompany loss of hypoglycaemia awareness in men with type 1 diabetes mellitus. An [11C]-3-O-methyl-D-glucose PET study. Diabetologia 48: 2080-2089. https://doi.org/10.1007/s00125-005-1900-6

32. Arbelaez AM, Powers WJ, Videen TO, Price JL, Cryer PE (2008) Attenuation of counterregulatory responses to recurrent hypoglycemia by active thalamic inhibition: A mechanism for hypoglycemiaassociated autonomic failure. Diabetes 57:470-475. https://doi.org/ $10.2337 / \mathrm{db} 07-1329$

33. Dunn JT, Choudhary P, Teh MM et al (2018) The impact of hypoglycaemia awareness status on regional brain responses to acute hypoglycaemia in men with type 1 diabetes. Diabetologia 61:1676-1687. https://doi.org/10.1007/s00125-018-4622-2

34. McNeilly AD, McCrimmon RJ (2018) Impaired hypoglycaemia awareness in type 1 diabetes: Lessons from the lab. Diabetologia 61:743-750. https://doi.org/10.1007/s00125-018-4548-8

35. Terpstra M, Moheet A, Kumar A, Eberly LE, Seaquist E, Öz G (2014) Changes in human brain glutamate concentration during hypoglycemia: Insights into cerebral adaptations in hypoglycemia-associated autonomic failure in type 1 diabetes. $\mathrm{J}$ Cereb Blood Flow Metab 34:876-882. https://doi.org/10.1038/ jcbfm.2014.32

36. Wiegers EC, Rooijackers HM, Tack CJ, Heerschap A, de Galan $\mathrm{BE}$, van der Graaf M (2016) Brain lactate concentration falls in response to hypoglycemia in patients with type 1 diabetes and impaired awareness of hypoglycemia. Diabetes 65:1601-1605. https://doi.org/10.2337/db16-0068

37. Rogers HA, de Zoysa N, Amiel SA (2012) Patient experience of hypoglycaemia unawareness in type 1 diabetes: Are patients appropriately concerned? Diabet Med 29:321-327. https://doi.org/10. 1111/j.1464-5491.2011.03444.x

38. Anderbro T, Gonder-Frederick L, Bolinder J et al (2015) Fear of hypoglycemia: Relationship to hypoglycemic risk and 
psychological factors. Acta Diabetol 52:581-589. https://oi.org/ 10.1007/s00592-014-0694-8

39. Smith CB, Choudhary P, Pernet A, Hopkins D, Amiel SA (2009) Hypoglycemia unawareness is associated with reduced adherence to therapeutic decisions in patients with type 1 diabetes: Evidence from a clinical audit. Diabetes Care 32:1196-1198. https://doi.org/ $10.2337 / \mathrm{dc} 08-2259$

40. Evans ML, Pernet A, Lomas J, Jones J, Amiel SA (2000) Delay in onset of awareness of acute hypoglycemia and of restoration of cognitive performance during recovery. Diabetes Care 23:893897. https://doi.org/10.2337/diacare.23.7.893

41. Dømgaard M, Bagger M, Rhee NA, Burton CM, Thorsteinsson B (2015) Individual and societal consequences of hypoglycemia: A cross-sectional survey. Postgrad Med 127:438-445. https://doi.org/ 10.1080/00325481.2015.1045815

42. Bailey TS, Ahmann A, Brazg R et al (2014) Accuracy and acceptability of the 6-day Enlite continuous subcutaneous glucose sensor. Diabetes Technol Ther 16:277-283. https://doi.org/10.1089/dia. 2013.0222

43. Hendrieckx C, Gonder-Frederick L, Heller SR, Snoek FJ, Speight J (2020) How has psycho-behavioural research advanced our understanding of hypoglycaemia in type 1 diabetes? Diabet Med 37:409417. https://doi.org/10.1111/dme.14205

Publisher's note Springer Nature remains neutral with regard to jurisdictional claims in published maps and institutional affiliations. 